\title{
Stability Analysis of Process Route Based on Weighted Network
}

\author{
Ying Xiang, Rong Mo, Zhiyong Chang, Hu Qiao, and Chunlei Li \\ The Key Laboratory of Contemporary Design and Integrated Manufacturing Technology, Ministry of Education, \\ Northwestern Polytechnical University, Xian 710072, China \\ Correspondence should be addressed to Ying Xiang; yingcara@hotmail.com
}

Received 26 June 2015; Accepted 2 November 2015

Academic Editor: Xiaobo Qu

Copyright (C) 2015 Ying Xiang et al. This is an open access article distributed under the Creative Commons Attribution License, which permits unrestricted use, distribution, and reproduction in any medium, provided the original work is properly cited.

Aiming at the production stability of complex parts, a method based on weighted network was proposed to analyze the stability of the process routes of complex parts in order to improve the production stability. The weighted network of the process routes of complex parts was constructed by using the concept of machining cell which can transform the production cost and manufacturing time to the weights of network to do the decision-making of the process routes. Based on the production stability, the brittleness risk entropy of subsystem of weighted network was constructed by analyzing the probability of the brittle events that may lead to the collapse of the weighted network in machining cells. As the indicator of analyzing the vulnerability of weighted network node, the brittleness risk entropy can predict the easily failed subsystem in the entire network. Meanwhile, the brittle event, which may lead to the machining cell failure, was retrospect for the greater stability of the process routes. Finally, the correctness and effectiveness of this method were verified by using the manufacturing process of an aero-engine blade.

\section{Introduction}

The diversity of process route in business production is derived from two sides. First, the order and methods of manufacturing features of parts are not unique. Second, the manufacturing resource in enterprise is various and similar. Next, there are many factors in production which may lead to the instability. For example, the factors like the irrational process routes which may lead to the imbalance of manufacturing resource and then trigger production faults and the brittle events (toll wear) which may delay the processing may cause catastrophic collapse of production. Therefore, as the hinge between the products design and manufacture, process route must be chosen with reason that can raise production efficiency and reduce costs and meanwhile avoid the occurrence of brittle events to increase the stability of business production.

Recently, the research shows some methods describing the process of parts manufacturing, which are the objectoriented method $[1,2]$, the petri net-based modeling method [3-5], discrete event dynamic simulation method [6,7], and so forth. These methods put the emphasis on describing and definition of the elements in manufacturing process, while lacking description of the correlation among the elements. Based on this, researchers proposed graph theory and complicated network modeling methods [8-12]. They imported these methods into practice and described the correlation of different elements preliminarily. This graph theory-based process route is subject to the theory of graph itself, so it is limited in long process route. In addition, this method emphasizes that process route is optimal in some ways, while ignoring the stability of process route.

In the research about the system stability, Fouad et al. first propose the concept of system vulnerability and build an analytic technique on vulnerability by using transient energy function (TEF) method and neural networks [13]. In 2000, Albert et al. research vulnerability source based on complicated theory [14]. Therefrom, they bring the system vulnerability into a new age. Xu and Wang put up a scalefree coupled map lattices (CML) model that is a good math method for cascading failures of complicated network [15]. Jin et al. research the system vulnerability by using the theory of entropy and systematic mutation [16]. Some results emphasizing theories are achieved, which aim at universality researches about complicated system. For manufacture system, due to its complicacy and specificity, there is discrepancy 


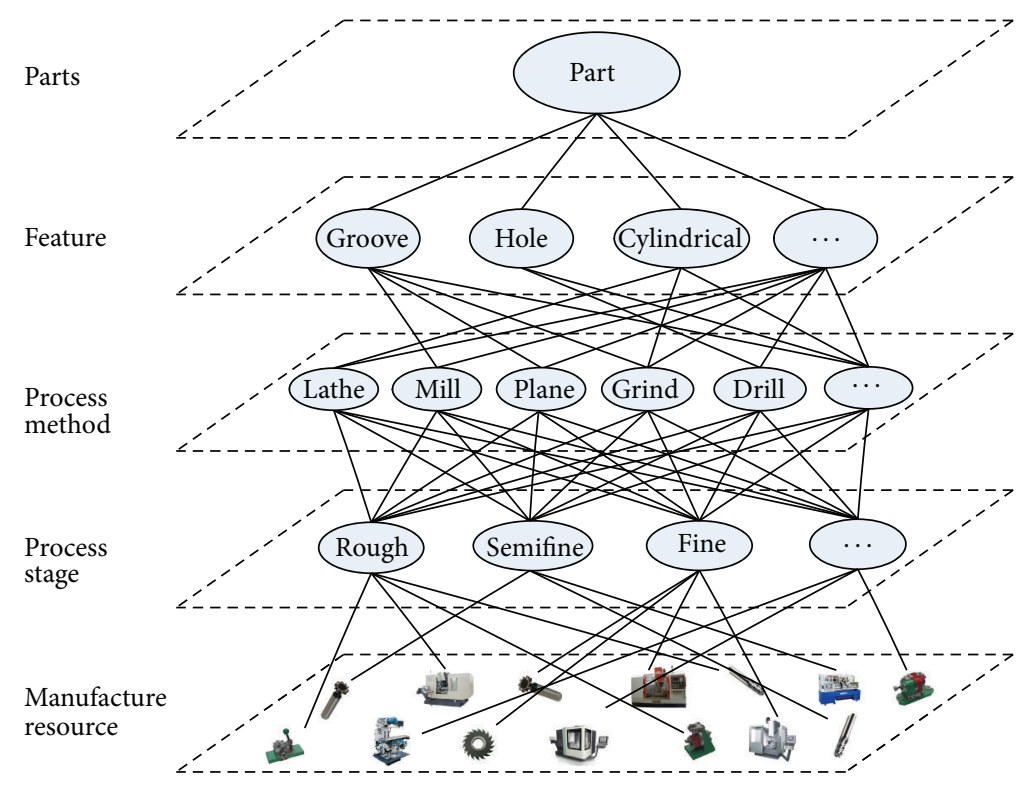

FIGURE 1: The hierarchical graph of parts processing.

between it and the common complicated system in system vulnerability field. Therefore, further efforts should be made to research it.

In this paper, a weighting network-supped process route method about complicated parts is put up based on production stability and system vulnerability. The weighted network of the process routes of complex parts was constructed by using machining cell. And then, the brittleness risk entropy of subsystem of weighted network was constructed by analyzing the probability of the brittle events. The brittle event, which may lead to the machining cell failure, was retrospect in order to improve the production stability. Also, the correctness and validity are verified by instance in this paper.

\section{The Weighted Network of the Process Routes of Complex Parts}

2.1. Machining Cell. Routings consist of some object-oriented manufacturing features which are arranged by the processing route and the connection among them. Beginning with the manufacturing features of elements, the route of process should be designed by considering different factors, such as the parts materials, the relationship among features, manufacture resource and the design experience of technologist, and so forth. It may be divided into these five steps: partsfeature-process method-process stage-manufacture resource (Figure 1).

Definition 1 (machining cell). The processing of characteristics of mechanical parts is sorted according to the principle "coarse to fine" to form a machining operation sequence, also known as the processing chain; each element in the processing chain is called "machining cell" [17]. It can be expressed as

$$
U_{a b}=\left\{F_{a}, L_{l}, G_{b}, D_{d}\right\}
$$

where $F_{a}$ is the ath manufacturing feature which belongs to the machining cell, such as hole, groove, and plane; $L_{l}$ is the processing method which belongs to $F_{a}$, for example, lathe, mill, plane, grind, and drill; $G_{b}$ is processing stage which belongs to $F_{a}$. Usually, there are rough machining, semifine machining, and fine machining. $D_{d}$ is manufacturing resources used in the processing stage, mainly referring to the machine, cutting, and fixture.

Therefore, a machining cell has only one manufacturing feature that may be a process and may also be a step. At the same time, a machining cell belongs to only one processing stage and one processing method and uses only one cutting and one machine. In the production line, all machining cell formed the high cohesion and low coupling station of having manufacturing capacity in a special way. And then, the roughcast can be processed between station and another station in the driving of the manufacturing technology. The product of meeting the design requirements was obtained ultimately.

2.2. The Construction of Weighted Network. Multistage machining processes have many machining processes and many coupling relationships among machining processes; thus complex network theory can be introduced in multistage machining processes.

In the design of process scheme for multistage machining processes, there are several process schemes that exist in interrelation with other machining cells in this scheme and the machining cell in the other process schemes. So the machining cells are mapped as weighted network nodes. Because the coupling relationships among machining cell are machining feature and datum relation, coupling relationships are mapped as edges among weighted network nodes. In machining process of product, as the production cost and manufacturing time are important characteristic and they are 
one of the important factors of the process scheme design that reflects the cost and efficiency, the production cost and manufacturing time are mapped as the weights of weighted network.

Depending on complex network theory, a weighted network of multistage machining scheme for complex parts manufacturing process is constructed by the weighted network nodes, the edges among weighted network nodes, and the weights of weighted network. Figure 2 shows the weighted network construction of multistage machining scheme for complex parts manufacturing process.

In Figure $2, U_{j}$ denotes the $j$ th machining cell; $P_{k}$ denotes the $k$ th stage machining process in complex parts manufacturing process; and $V_{j}$ denotes the $j$ th note in the weighted network of complex parts manufacturing process.

$W$ is defined as weight matrix among weighted network nodes, so $W=\left[w_{1,1}, w_{1,2}, \ldots, w_{h, j}\right]_{n \times n} ; w_{h, j}(0 \leq h \leq n, 0 \leq$ $j \leq n)$ is the weight of weighted network from $h$ th to $j$ th and denotes the production cost and manufacturing time of machining cell.

Definition 2. The number of adjacent nodes with $V_{j}$ is the degree of $V_{j}$, denoted as $k_{j}$.

Corollary 3. The number of adjacent nodes pointing to $V_{j}$ is the out-degree of $V_{j}$, denoted as $k_{j}^{\text {out }}$. The out-degree is the influence scope of processing capacity of machining cell.

Corollary 4. The number of adjacent nodes pointing to $V_{j}$ is the in-degree of $V_{j}$, denoted as $k_{j}^{\text {in }}$. The in-degree is the scope of processing objects of machining cell.

Definition 5. The strength of nodes $s_{j}$ is the connection ability of $V_{j}$ and other nodes:

$$
s_{j}=\sum_{h \in \alpha} w_{j h}
$$

where $\alpha$ is the number set of adjacent nodes with $V_{j}$.

Corollary 6. The strength of nodes $s_{j}^{\text {out }}$ is the connection ability of $V_{j}$ and adjacent nodes pointing to $V_{j}$, and $s_{j}^{\text {out }}$ is the influence extent of processing capacity of machining cell:

$$
s_{j}^{\text {out }}=\sum_{h \in \beta} w_{j h},
$$

where $\beta$ is the number set of adjacent nodes pointing to $V_{j}$.

Corollary 7. The strength of nodes $s_{j}^{\text {in }}$ is the connection ability of $V_{j}$ and adjacent nodes pointing to $V_{j}$, and $s_{j}^{\text {in }}$ is the assignment amount of machining cell:

$$
s_{j}^{\text {in }}=\sum_{h \in \gamma} w_{j h}
$$

where $\gamma$ is the number set of adjacent nodes pointing to $V_{j}$.
Definition 8. The clustering coefficient is the influence extent of the clustering degree of adjacent nodes for this node in weighted network. The bigger the clustering degree of nodes is, the higher the key degree of machining cell is. In weighted network, $c_{j}$ is expressed as

$$
c_{j}=\frac{1}{s_{j}\left(k_{j}-1\right)} \cdot \sum_{h, l \in \alpha} \frac{\left(w_{j, h}+w_{k, l}\right)}{2}\left(a_{j h} a_{h l} a_{l j}\right) .
$$

\section{The Decision-Making Model of Multistage Process Routes}

In weighted network, machining cells are regarded as network nods, which represent different manufacturing phases, manufacturing methods, and manufacturing resources. Because there are various manufacturing methods and resources in every phase, the whole process may produce various process routes in weighted network. That is to say, we must do decision-making in different process routes to select the most reasonable one that can guide the manufacturing process.

The designer usually designs multiple process routes which contrapose one part. Different routes mean different cost and time in practice. The paper aims at the manufacturing costs and time and does decision-making in various routes to pursue the most reasonable weight in weighting network.

3.1. The Production Cost. The total cost of parts manufacturing includes two parts: the production cost $\left(M_{\text {in }}\right)$ and the changing cost $\left(M_{q}\right)$. The machining cell is used as the node in this paper. The machine cost and tool cost are totally called the inner production cost $\left(M_{\mathrm{in}}\right)$ of machining cell. In this network, the cost changing between adjacent nodes is called the changing cost $\left(M_{q}\right)$. For example, if different production processes need different machines in manufacturing, $M_{q}$ is cost of changing one machine to another which includes the cost of labor and transportation. Consequently, in the process route in practice, if there are $m$ kinds of routes, $n$ machining cells in one process route, the mathematical models of $M_{i}$ in $i$ th route may be described as

$$
\begin{aligned}
M_{i}=\left(M_{\mathrm{in}}+M_{q}\right)=\left(\sum_{j=1}^{n} M_{i, j}+\sum_{j=1}^{n-1} M_{i,(j, j+1)}\right) \\
i=1,2, \ldots, m, j=1,2, \ldots, n,
\end{aligned}
$$

where $M_{i, j}$ is the inner production cost of node $j$ in the $i$ th process route; $M_{i,(j, j+1)}$ is the changing cost from node $j$ to node $j+1$ in the $i$ th process route.

3.2. Manufacturing Time. The manufacturing time includes machining time and transportation time. Consequently, in the process route in practice, if there are $m$ kinds of routes, $n$ machining cells in one process route, the 


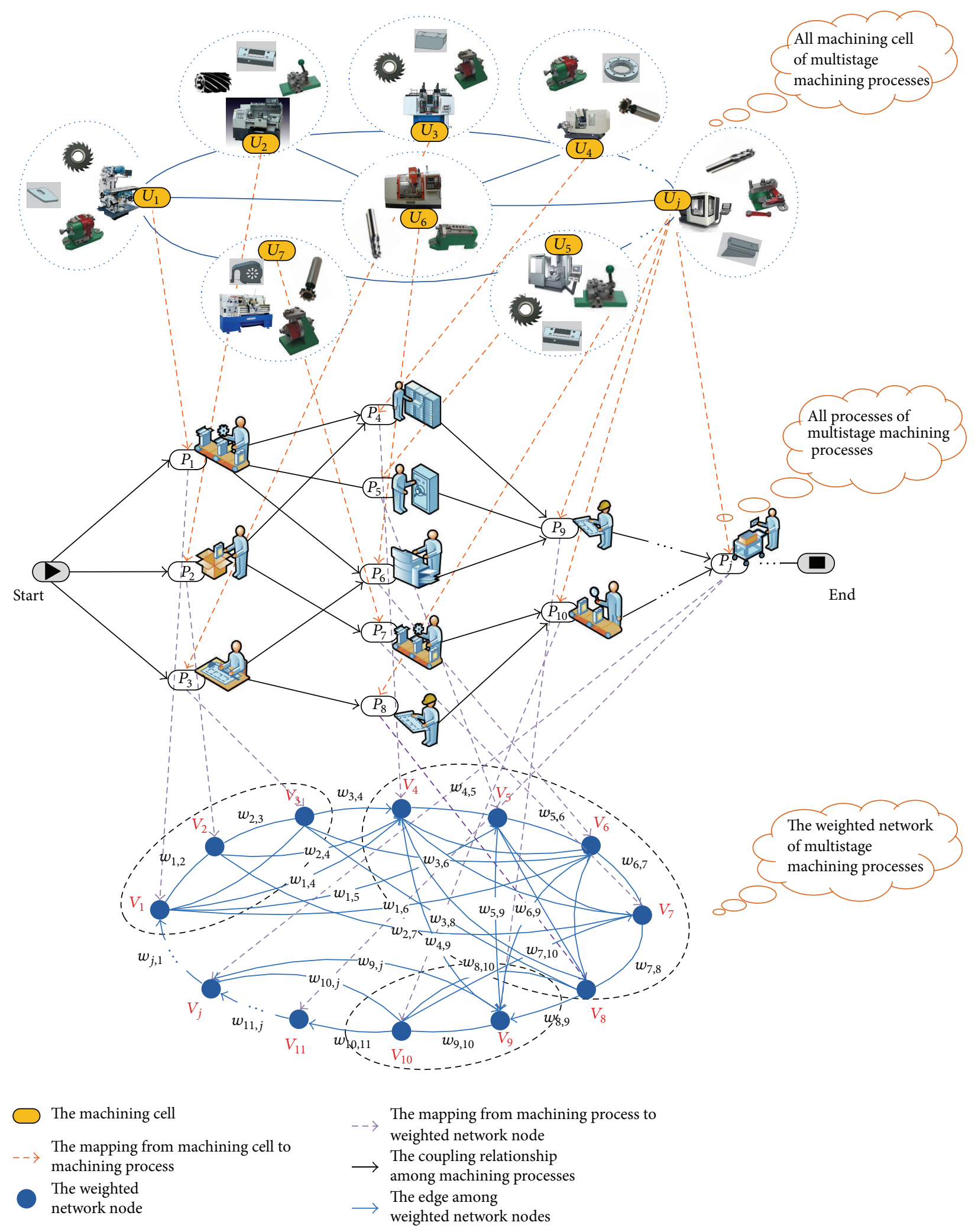

FIGURE 2: The weighted network construction of multistage machining process. 
mathematical models of $T_{i}$ in $i$ th route may be described as

$$
\begin{aligned}
T_{i}=\left(T_{0}+T_{\mathrm{tr}}\right)=\left(\sum_{j=1}^{n} T_{i, j}+\sum_{j=1}^{n-1} T_{i,(j, j+1)}\right) \\
\quad i=1,2, \ldots, m, j=1,2, \ldots, n,
\end{aligned}
$$

where $T_{i, j}$ is the machining time of the node $j$ in the $i$ th process route; $T_{i,(j, j+1)}$ is the transportation time between the node $j$ and node $j+1$ in the $i$ th process route.

By the means of the multiprocess route decision model mentioned above, we can get the ultimate machining cell by selecting the useful one, meanwhile judging whether the cell is in practicable status or not. The relationship among the machining cells shapes the multiprocess route decision network, and the useful machining cells form the nodes in this network. The weight of the network is the production cost and manufacturing time. It can be analyzed to get the most suitable decision to make the best balance between the production cost and manufacturing time. Due to considering the production cost and manufacturing time overall, the multiprocess route decision model is a kind of multiple target. In general, the math model of the multiprocess route decision mentioned above can be described as

$$
f\left(M_{i}, T_{i}\right)=\frac{k_{1}}{M_{i}}+\frac{k_{2}}{T_{i}} .
$$

So

$$
\begin{aligned}
f\left(M_{i}, T_{i}\right)= & \frac{k_{1}}{\left(\sum_{j=1}^{n} M_{i, j}+\sum_{j=1}^{n-1} M_{i,(j, j+1)}\right)} \\
& +\frac{k_{2}}{\left(\sum_{j=1}^{n} T_{i, j}+\sum_{j=1}^{n-1} T_{i,(j, j+1)}\right)} \\
k_{1}+k_{2}= & 1, \quad k_{1}, k_{2} \in[0,1], \ldots, m, j=1,2, \ldots, n
\end{aligned}
$$

where adjusting $k_{1}$ and $k_{2}$ will decide the focus of process scheme decisions.

Currently, for the multifunction of the process route decision, there are abundant algorithms provided by the correlative papers [17-20]. This paper solves the multiprocess route decision model by the Adaptive Ant Colony Algorithm proposed by Chang et al. [17]; there is no longer repetition.

\section{The Vulnerability Analysis of Machining Cell}

In the process decision method, there may be a variety of reasonable process routes, but the machining cell may often be due to abnormal processing equipment which hindered the process. So we need to analyze the abnormal probability of machining cell in order to obtain the most reasonable and high stability process route.

Therefore, it is necessary to analyze the brittle risk of machining cell in order to grasp the abnormal probability of machining cell. That may improve the stability of the process route.

In weighting network the process routes of complex parts, taking the machining cell as the node of the network, the network $S$ is configured by $n$ subnetwork if taking the machining cell $U_{j}$ as subsystem of the network $S$, may be expressed as $S_{j}$, so $S=\left\{S_{1}, S_{2}, \ldots, S_{n}\right\}$.

According to formula (8), the reasonable process route is obtained in weighted network of the process routes of complex parts. In the machining process of part, the brittle events (tool wear, equipment load, etc.) may cause the system malfunction in subsystem (i.e., there is brittle risk in subsystem). Along with the transfer and expansion of the collapse behavior, thereby the entire manufacturing process may be paralyzed. Brittleness risk of network system is the risk of subsystem failure because the brittleness of subsystem is stimulated. It is considered that the fundamental source of brittleness risk of the entire system is the uncertainty of brittle events of subsystem. So the subsystem failure triggered by brittle event is needed to be predicted and controlled in order to ensure the stability of the weighted network of the process route of complex parts.

If the subsystem $S_{j}$ has brittle events $E=\left\{E_{1}, E_{2}, \ldots, E_{t}\right\}$, the probability of brittle event $E_{r}(r=1,2, \ldots, t)$ is $p_{r}$; there is a basic relationship:

$$
\sum_{r=1}^{t} p_{r}=1, \quad 0 \leq p_{r} \leq 1 .
$$

The probability of subsystem occurrence failure is $q_{r}$ under the action of the brittle event $E_{r}$, and $0 \leq q_{r} \leq 1$, so the probability $P_{S j}$ of subsystem occurrence failure due to brittle events is shown as

$$
P_{S_{j}}=1-\prod_{r=1}^{t}\left(1-p_{r} q_{r}\right) \quad j=1,2, \ldots, n .
$$

The influence coefficient, the failure of machining cell effect collapse of the weighted network, is defined as $\xi$. That is, in the network system $S=\left\{S_{1}, S_{2}, \ldots, S_{n}\right\}$, the influence coefficient, the failure of subsystem $S_{j}$ effect collapse of the system $S$, is defined as $\xi_{j}$. The influence coefficient and weighting network clustering coefficient have a similar function, so the influence coefficient $\xi_{j}$ may be mapped as the normalized values of the clustering coefficient:

$$
\xi_{j}=\frac{c_{j}}{\sum_{j=1}^{n} c_{j}} .
$$

The effective coefficient of subsystem $S_{j}$ collapse is the normalized values of subsystem collapse probability and influence coefficient:

$$
\begin{gathered}
g_{j}=\frac{P_{s_{j}} \xi_{j}}{\sum_{j=1}^{n} P_{s_{j}} \xi_{j}}, \\
\sum_{j=1}^{n} g_{j}=1, \quad 0 \leq g_{j} \leq 1 .
\end{gathered}
$$




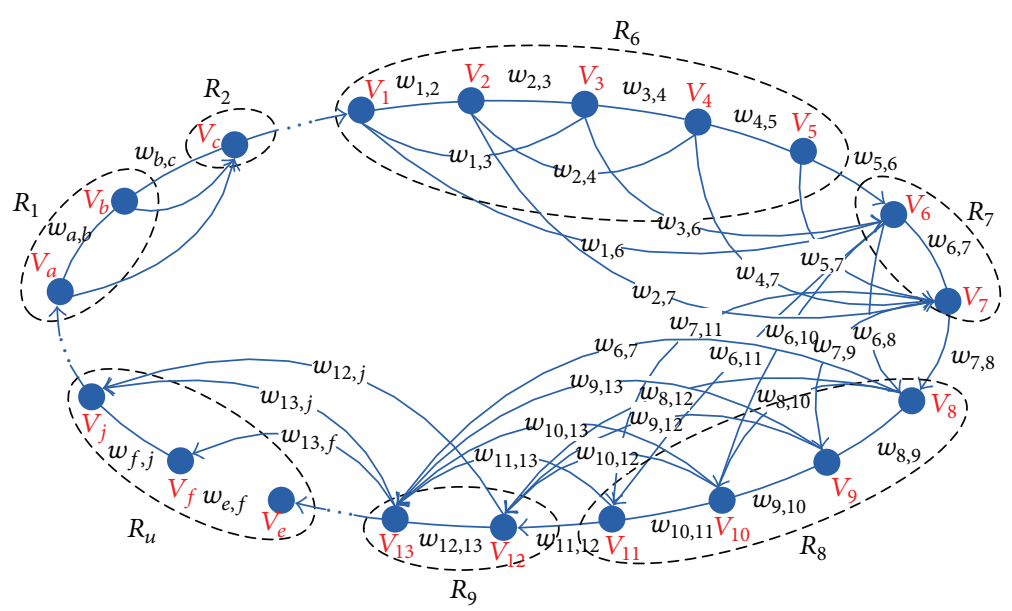

FIGURE 3: The weighted network of blade machining processes.

According to Shannon theory [21], the brittleness risk entropy $H(S)$ of subsystem $S_{j}$ is defined as the average value of the risk probability of brittle event in utility coefficient space, expressed as

$$
H\left(s_{j}\right)=-g_{j} \log P_{s_{j}} .
$$

So

$$
\begin{aligned}
H\left(S_{j}\right)= & -\frac{\left(1-\prod_{r=1}^{t}\left(1-p_{r} q_{r}\right)\right)\left(c_{j} / \sum_{j=1}^{n} c_{j}\right)}{\sum_{j=1}^{n}\left(1-\prod_{r=1}^{t}\left(1-p_{r} q_{r}\right)\right)\left(c_{j} / \sum_{j=1}^{n} c_{j}\right)} \\
& \cdot \log \left(1-\prod_{r=1}^{t}\left(1-p_{r} q_{r}\right)\right) .
\end{aligned}
$$

Brittleness risk entropy of subsystem can reflect not only the fundamental source of subsystem brittle which is uncertain of brittle events, but also influence of collapse coefficient. Brittleness risk entropy of subsystem combines these both effects for system brittleness risk effectively [16]. Brittleness risk entropy is used to measure brittleness risk probability of subsystem $S_{j}$ in a moment, which is the uncertainty measurement of subsystem possible collapse, and may predict the brittleness risk of subsystem.

Formula (14) shows that there is a close relationship between the subsystem brittleness risk entropy and the node clustering coefficient that is topological properties of the weighted network, so weighting network of the complex parts processing, having different topological properties, has different subsystem brittleness risk entropy. Through the analysis of the subsystem of brittleness risk entropy, the brittleness risk entropy of each machining cell and the brittleness risk entropy of the process route which have the machining cell can be obtained. The minimum brittleness risk entropy of the process route, namely, the highest stability process route, can be obtained by analyzing the brittleness risk entropy of process route. In the production, the higher stability and reasonable process route can guarantee the stability of production.

\section{Case Study}

An experiment case of the manufacturing process of an aeroengine blade [21] is performed to verify the effectiveness of this method. The engine manufacturers have advanced blade machining centers that introduce a large number of advanced types of equipment, such as axis CNC machine tools and five-axis $\mathrm{CNC}$ machine tools. According to the actual situation of the enterprise, the aero-engine blade design requirements, manufacturing costs, and production time basis, the proposed method is verified.

The weighted network of blade machining process is formed by the intrinsic link between each technology program, in the enterprise. In this network, one of the aeroengine blade machining tasks may have a variety of processing methods, and each processing method can be achieved through multiple processing element. In the preparation process, the weighted network of the machining process, regarding machining cell as node, is formed by considering variety of resources for each processing element and different conditions, shown in Figure 3. Due to the complexity of machining aerospace engine blades, limited space of this paper, an experiment case of a part of the blade manufacturing features is used to explain the building process of the weighted network.

The portion process of the blade and the information of the required machining cell are shown in Table 1 , and the various processing tasks shown in Table 1 may be completed by the corresponding machining cell shown in Table 2 .

The blade processing has 36 different technology programs from craft station of the blade top to positioning holes of craft station from Table 2, because of the multiple choice of the processing methods from 6 to 9 , and the machining cells matched the processing methods, as shown in Figure 3. In processing blade, the local factory focuses on manufacturing 
TABle 1: Process tasks of a blade.

\begin{tabular}{llcccc}
\hline Task & Process task & Process method & Accuracy class & $\begin{array}{c}\text { Surface roughness } \\
\text { Ra/ } \mu \mathrm{m}\end{array}$ & Note \\
\hline$R_{6}$ & Blade top craft station & Milling & IT10 & 3.2 & $\begin{array}{l}\text { Poor milling, CNC machining, special } \\
\text { fixtures }\end{array}$ \\
\hline$R_{7}$ & $\begin{array}{l}\text { Blade dorsal } \\
\text { positioning surface }\end{array}$ & Milling & IT10 & 3.2 & Four-axis CNC machining, special fixtures \\
\hline$R_{8}$ & Tenon root & Wire cutting & IT10 & 3.2 & CNC wire-cutting machine, special fixtures \\
\hline$R_{9}$ & $\begin{array}{l}\text { Positioning holes of } \\
\text { craft station }\end{array}$ & Drilling & IT9 & 3.2 & Four-axis CNC machining, special fixtures \\
\hline$\vdots$ & $\vdots$ & $\vdots$ & $\vdots$ & $\vdots$ & $\vdots$ \\
\hline
\end{tabular}

TABLE 2: The machining cell information matched with process tasks.

\begin{tabular}{|c|c|c|c|c|c|c|c|c|}
\hline Task & $\begin{array}{c}\text { The number } \\
\text { of optional } \\
\text { machining } \\
\text { cells }\end{array}$ & $\begin{array}{c}\text { The number } \\
\text { of corre- } \\
\text { sponding } \\
\text { nodes }\end{array}$ & $\begin{array}{l}\text { The } \\
\text { processing } \\
\text { method }\end{array}$ & $\begin{array}{l}\text { Accuracy } \\
\text { class }\end{array}$ & $\begin{array}{c}\text { Surface } \\
\text { roughness } \\
\mathrm{Ra} / \mu \mathrm{m}\end{array}$ & $\begin{array}{l}\text { The location of } \\
\text { machining cell }\end{array}$ & $\begin{array}{c}\text { Production } \\
\text { cost } \\
\text { (thousand) }\end{array}$ & $\begin{array}{l}\text { Manufacturing } \\
\text { time (day) }\end{array}$ \\
\hline \multirow{5}{*}{$R_{6}$} & $U_{61}$ & $V_{1}$ & \multirow{5}{*}{ Milling } & $11 \sim 7$ & $6.4 \sim 3.2$ & Other factories & 0.6 & 1 \\
\hline & $U_{62}$ & $V_{2}$ & & $10 \sim 7$ & $6.4 \sim 1.6$ & Other factories & 0.5 & 2 \\
\hline & $U_{63}$ & $V_{3}$ & & $10 \sim 7$ & $6.4 \sim 1.6$ & Other factories & 0.55 & 2 \\
\hline & $U_{64}$ & $V_{4}$ & & $11 \sim 7$ & $6.4 \sim 3.2$ & Other factories & 0.45 & 2 \\
\hline & $U_{65}$ & $V_{5}$ & & $10 \sim 7$ & $6.4 \sim 1.6$ & Local factory & 0.8 & 1 \\
\hline \multirow{2}{*}{$R_{7}$} & $U_{71}$ & $V_{6}$ & \multirow{2}{*}{ Milling } & $10 \sim 6$ & $6.4 \sim 3.2$ & Local factory & 1.2 & 1 \\
\hline & $U_{72}$ & $V_{7}$ & & $9 \sim 5$ & $6.4 \sim 0.8$ & Local factory & 1.8 & 1 \\
\hline \multirow{4}{*}{$R_{8}$} & $U_{81}$ & $V_{8}$ & \multirow{4}{*}{$\begin{array}{l}\text { Wire } \\
\text { cutting }\end{array}$} & $12 \sim 8$ & $6.4 \sim 3.2$ & Other factories & 0.2 & 2 \\
\hline & $U_{82}$ & $V_{9}$ & & $10 \sim 7$ & $6.4 \sim 1.6$ & Other factories & 0.2 & 3 \\
\hline & $U_{83}$ & $V_{10}$ & & $12 \sim 8$ & $6.4 \sim 3.2$ & Other factories & 0.15 & 2 \\
\hline & $U_{84}$ & $V_{11}$ & & $9 \sim 5$ & $6.4 \sim 0.8$ & Other factories & 0.3 & 2 \\
\hline \multirow{2}{*}{$R_{9}$} & $U_{91}$ & $V_{12}$ & \multirow{2}{*}{ Drilling } & $10 \sim 6$ & $6.4 \sim 3.2$ & Local factory & 1.8 & 1 \\
\hline & $U_{92}$ & $V_{13}$ & & $9 \sim 5$ & $6.4 \sim 0.8$ & Local factory & 2.2 & 1 \\
\hline$\vdots$ & $\vdots$ & $\vdots$ & $\vdots$ & $\vdots$ & $\vdots$ & $\vdots$ & $\vdots$ & $\vdots$ \\
\hline
\end{tabular}

time; therefore, assuming that $k_{1}=0.3, k_{2}=0.7$, the decision function of preferred technology program is as follows:

$$
\begin{aligned}
f(M, T)= & \frac{0.3}{\left(\sum_{j=1}^{n} M_{i, j}+\sum_{j=1}^{n-1} M_{i,(j, j+1)}\right)} \\
& +\frac{0.7}{\left(\sum_{j=1}^{n} T_{i, j}+\sum_{j=1}^{n-1} T_{i,(j, j+1)}\right)} .
\end{aligned}
$$

In the weighted network of blade manufacturing, the decision indexes of every technology program are shown in Table 3. There is a part of program index because of the limited space, in route $3\left(V_{1}-V_{6}-V_{10}-V_{12}\right)$, route $30\left(V_{5}-V_{6}\right.$ $\left.V_{10}-V_{12}\right)$, route $31\left(V_{5}-V_{6}-V_{10}-V_{13}\right), f 3=0.3 / 3.9+0.7 / 15=$ $0.12359, f 30=0.3 / 4.3+0.7 / 12=0.128101$, and $f 31=$ $0.3 / 4.35+0.7 / 13=0.122812$.

The production cost and manufacturing time are the most reasonable in these programs.

Nodes' vulnerability is related to clustering coefficient closely in the weighted network of this blade. According to formula (4), nodes' clustering coefficients are derived and the distribution is shown in Figure 4.
Formula (14) derives that node $V_{6}$ 's Brittleness risk entropy is the highest, as shown in Figure 5. In the reasonable process routes, the node $V_{1}$ corresponding to the machining cell $U_{61}$ and the node $V_{5}$ corresponding to the machining cell $U_{65}$ can be selected; the node $V_{12}$ corresponding to the machining cell $U_{91}$ and the node $V_{13}$ corresponding to the machining cell $U_{92}$ can be selected. Thus, the route 30 is better than route 3 because that brittleness risk entropy of $V_{1}$ is greater than brittleness risk entropy of $V_{5}$. The route 30 is better than route 31 because that brittleness risk entropy of $V_{12}$ is greater than brittleness risk entropy of $V_{13}$. Therefore, the route $30\left(V_{5}-V_{6}-V_{10}-V_{12}\right)$ is the highest stability process route.

During the manufacturing process of aero-engine blade, node $V_{6}$ corresponds to machine cell $U_{71}$ and by Figure 5 we derive that $V_{6}$ is prone to collapse. Machine cell $U_{71}$ is a part of most reasonable process route. By analyzing the event that triggered machine cell $U_{71}$ collapses, we find that the most important reason is this machine cell easily overloaded. So enterprise should arrange $U_{71}$ corresponding fouraxis CNC machine's usage reasonable in the manufacturing 
TABLE 3: The evaluation of a part of craft program.

\begin{tabular}{|c|c|c|c|c|c|c|c|c|c|c|c|c|c|c|c|c|c|c|c|c|c|}
\hline \multirow{3}{*}{ Program } & \multicolumn{21}{|c|}{ Optional technology program } \\
\hline & \multicolumn{4}{|c|}{ Program 1} & \multicolumn{4}{|c|}{ Program 2} & \multicolumn{4}{|c|}{ Program 3} & \multicolumn{4}{|c|}{ Program 4} & \multicolumn{4}{|c|}{ Program 5} & $\ldots$ \\
\hline & 1 & 6 & 8 & 12 & 1 & 6 & 8 & 13 & 1 & 6 & 10 & 12 & 1 & 6 & 10 & 13 & 1 & 6 & 11 & 12 & $\cdots$ \\
\hline Production cost $M$ & \multicolumn{4}{|c|}{4.05} & \multicolumn{4}{|c|}{1.4} & \multicolumn{4}{|c|}{3.9} & \multicolumn{4}{|c|}{3.95} & \multicolumn{4}{|c|}{4.15} & $\cdots$ \\
\hline Manufacturing time $T_{0}$ & & \multicolumn{3}{|c|}{17} & \multicolumn{4}{|c|}{16} & \multicolumn{4}{|c|}{15} & \multicolumn{4}{|c|}{16} & \multicolumn{4}{|c|}{17} & $\cdots$ \\
\hline Decision function value & & \multicolumn{3}{|c|}{0.115251} & \multicolumn{4}{|c|}{0.111932} & \multicolumn{4}{|c|}{0.12359} & \multicolumn{4}{|c|}{0.119699} & \multicolumn{4}{|c|}{0.113466} & $\ldots$ \\
\hline
\end{tabular}

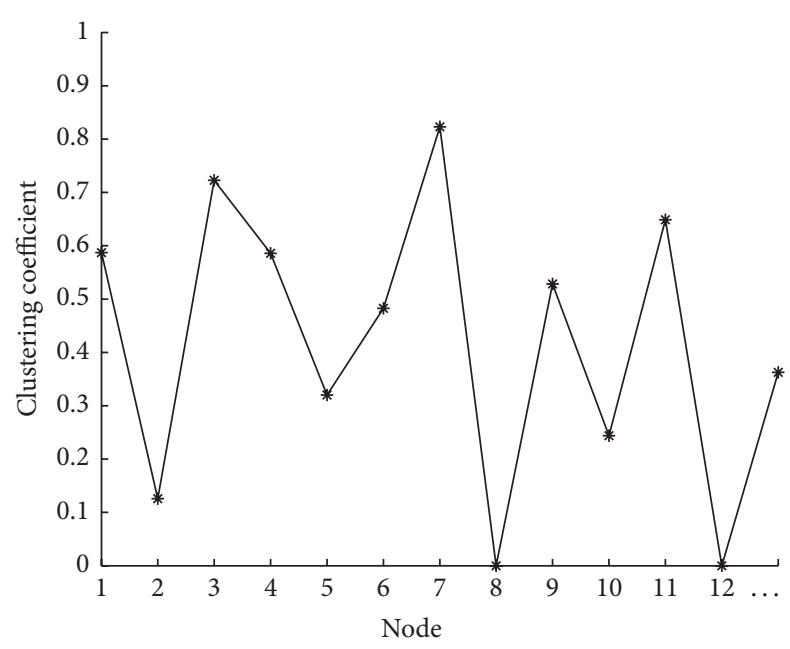

Figure 4: The clustering coefficients of a part of nodes.

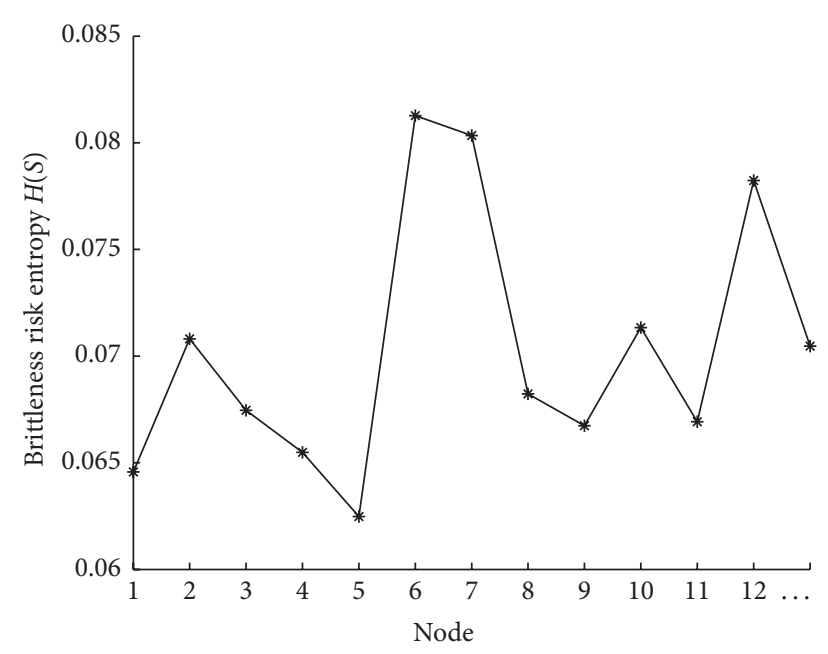

FIgURE 5: The brittleness risk entropy of a part of nodes.

process to avoid production disruption caused by four-axis CNC machine overload. This is consistent with the actual production.

\section{Conclusions}

(1) Based on part's manufacturing feature, weighted network of the process routes of complex parts is established by using machine cell, and the topological characteristics of weighted network are analyzed.
(2) Through transforming production cost and manufacturing time to the weight of network, the multiprocess routes decision-making of weighted network mathematical model is established to make process route decision.

(3) The factors lead to weighted network collapse which is analyzed to establish brittleness risk entropy of the subsystem of weighted network to obtain the highest stability process route.

(4) Proposed method is used to establish the weighted network of one aero-engine blade manufacturing process to choose the reasonable manufacturing process route. Thereby the effectiveness of the proposed method is verified by analyzing the vulnerability of weighted network nodes.

(5) The further research area will focus on deriving the substitute of brittle machine cell quickly according to brittle distance theory of complex network and analyzing the pattern of system brittleness propagation.

\section{Conflict of Interests}

The authors declare that there is no conflict of interests regarding the publication of this paper.

\section{Acknowledgment}

The project was supported by the National Natural Science Foundation of China (51375359).

\section{References}

[1] Y. N. Sotskov, A. Dolgui, and M.-C. Portmann, "Stability analysis of an optimal balance for an assembly line with fixed cycle time," European Journal of Operational Research, vol. 168, no. 3, pp. 783-797, 2006.

[2] X. Shao and Y. Rao, Manufacturing System Operation Optimization Theory and Methods, Science Press, Beijing, China, 2010.

[3] M. Uzam, "The use of the Petri net reduction approach for an optimal deadlock prevention policy for flexible manufacturing systems," International Journal of Advanced Manufacturing Technology, vol. 23, no. 3-4, pp. 204-219, 2004.

[4] G. Meja, C. Montoya, J. Cardona, and A. L. Castro, "Petri nets and genetic algorithms for complex manufacturing systems scheduling," International Journal of Production Research, vol. 50, no. 3, pp. 791-803, 2012. 
[5] Z. Cai, "Timed reconfigurable petri net-based modeling of reconf igurable manufacturing system," Acta Aeronautica et Astronautica Sinica, vol. 25, no. 6, pp. 615-618, 2004.

[6] B. Bouslah, A. Gharbi, R. Pellerin, and A. Hajji, "Optimal production control policy in unreliable batch processing manufacturing systems with transportation delay," International Journal of Production Research, vol. 51, no. 1, pp. 264-280, 2013.

[7] Q. Wang and C. R. Chatwin, "Key issues and developments in modelling and simulation-based methodologies for manufacturing systems analysis, design and performance evaluation," International Journal of Advanced Manufacturing Technology, vol. 25, no. 11-12, pp. 1254-1265, 2005.

[8] X.-H. Liu, X.-T. Zhang, and W.-J. Liu, "Multi-process routes decision-making methodology based on improved max-min ant system," Computer Integrated Manufacturing Systems, vol. 14, no. 12, pp. 2414-2420, 2008.

[9] Y. Qin, L. Zhao, Y. Yao, and D. Xu, "Multistage machining processes variation propagation analysis based on machining processes weighted network performance," The International Journal of Advanced Manufacturing Technology, vol. 55, no. 58, pp. 487-499, 2011.

[10] T. Yang, D. Zhang, B. Chen, and S. Li, "Capacity planning for mixed production line based on directed weighted networks," China Mechanical Engineering, vol. 22, no. 7, pp. 824-829, 2011.

[11] F. Jia, P. Jiang, D. Liu et al., "Error propagation control method for multistage batches machining process of blades," Computer Integrated Manufacturing Systems, vol. 18, no. 1, pp. 76-86, 2012.

[12] W.-J. Huang, L.-G. Cai, Y.-J. Hu, X.-L. Wang, and L. Ling, "Process planning optimization based on genetic algorithm and topological sort algorithm for digraph," Computer Integrated Manufacturing Systems, vol. 15, no. 9, pp. 1770-1778, 2009.

[13] A. A. Fouad, Q. Zhou, and V. Vittal, "System vulnerability as a concept to assess power system dynamic security," IEEE Transactions on Power Systems, vol. 9, no. 2, pp. 1009-1015, 1994.

[14] R. Albert, H. Jeong, and A.-L. Barabási, “The internet's achilles heel: error and attack tolerance of complex networks ," Nature, vol. 406, pp. 378-382, 2000.

[15] J. Xu and X. F. Wang, "Cascading failures in scale-free coupled map lattices," Physica A: Statistical Mechanics and its Applications, vol. 349, no. 3-4, pp. 685-692, 2005.

[16] H.-Z. Jin, Q. Wei, J. Guo et al., Brittle Theory and Application of Complex Systems, Northwestern Polytechnical University Press, Xian, China, 2010.

[17] Z. Chang, J. Yang, J. Zhao, and H. Wei, "Optimization of process based on adaptive ant colony algorithm," Chinese Journal of Mechanical Engineering, vol. 48, no. 9, pp. 163-169, 2012.

[18] M. K. Tiwari, Y. Dashora, S. Kumar, and R. Shankar, "Ant colony optimization to select the best process plan in an automated manufacturing environment," Proceedings of the Institution of Mechanical Engineers, Part B. Journal of Engineering Manufacture, vol. 220, no. 9, pp. 1457-1472, 2006.

[19] A. G. Krishna and K. M. Rao, "Optimisation of operations sequence in CAPP using an ant colony algorithm," The International Journal of Advanced Manufacturing Technology, vol. 29, no. 1-2, pp. 159-164, 2006.

[20] P. Wang, D.-H. Zhang, B. Chen, S. Li, and G.-H. Ma, "Evaluation of multi-process plans based on fuzzy comprehensive evaluation and grey relational analysis," Journal of Aerospace Power, vol. 27, no. 9, pp. 2075-2085, 2012.

[21] H. Jin, Q. Wei, J. Guo et al., Brittle Theory and Application of Complex Systems, Northwestern Polytechnical University Press, Shanghai, China, 2010. 


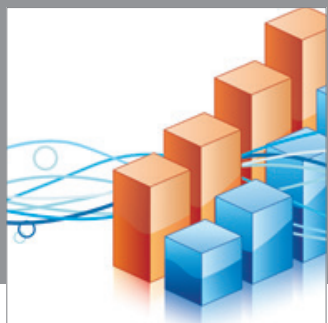

Advances in

Operations Research

mansans

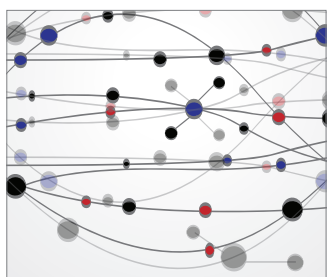

The Scientific World Journal
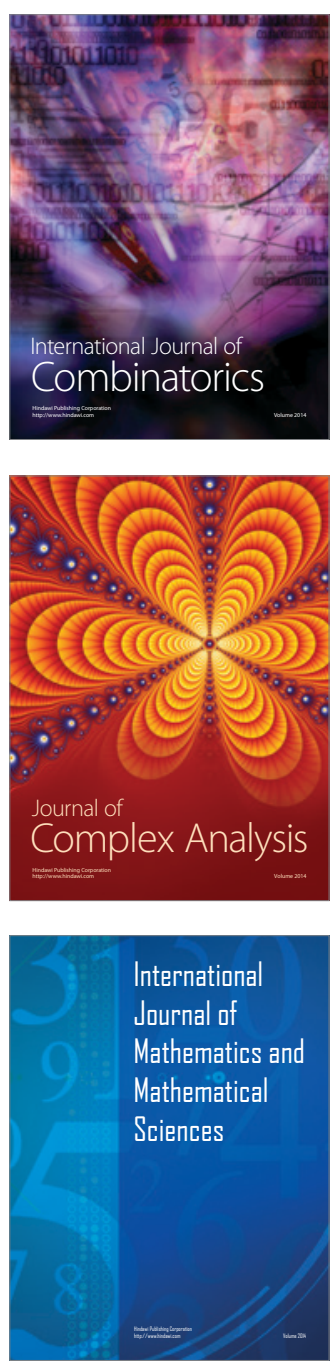
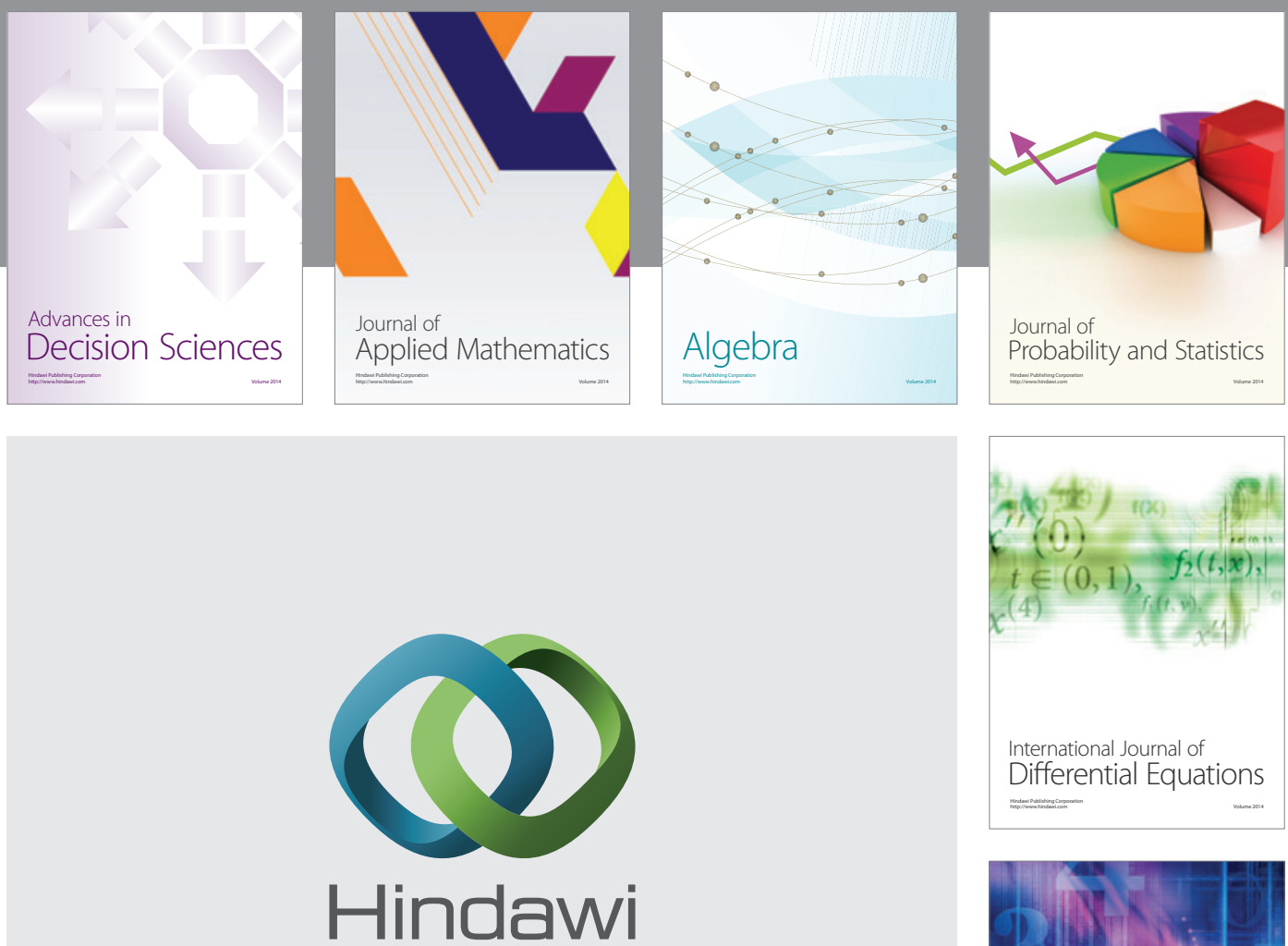

Submit your manuscripts at http://www.hindawi.com
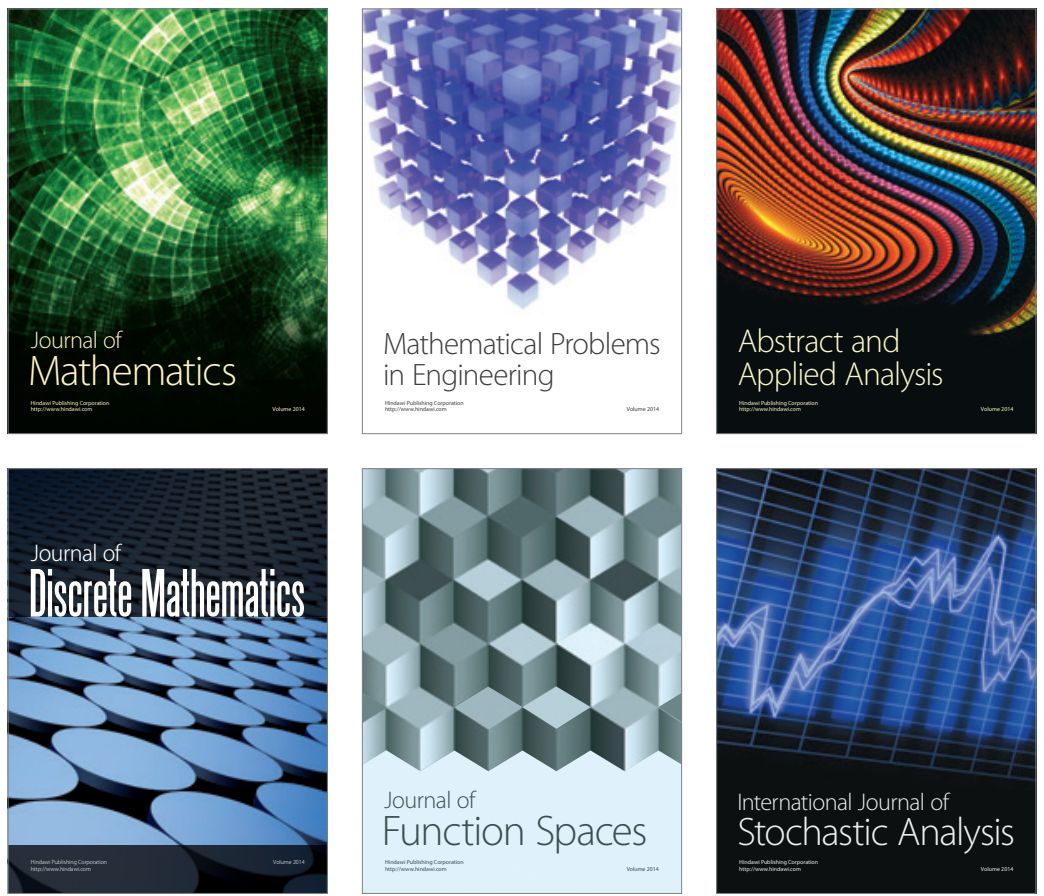

Journal of

Function Spaces

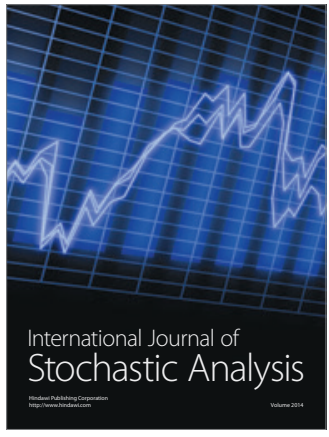

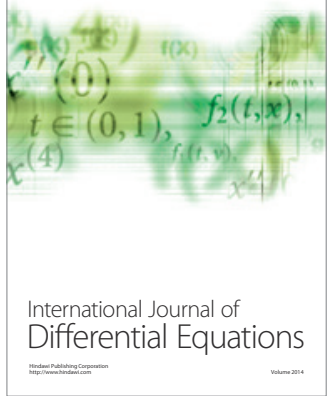
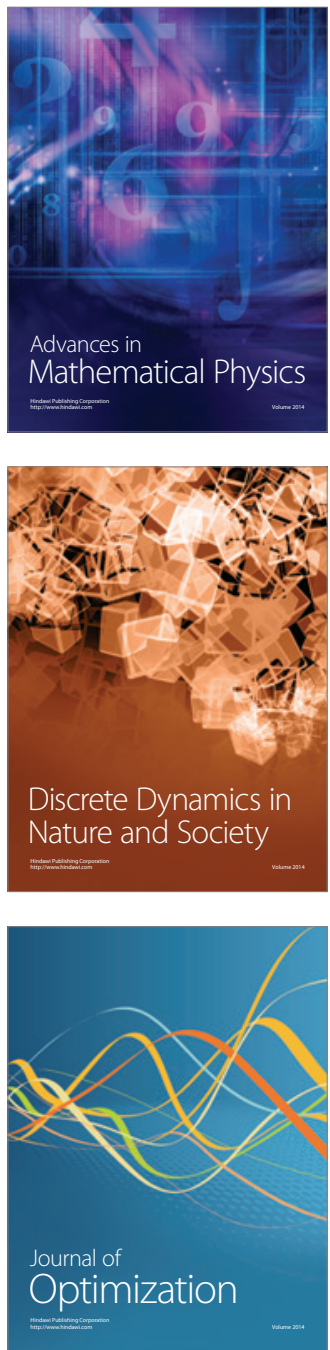